\title{
Translating Culture-specific Elements in Names in Hong Lou Meng: A Comparison of The Story of the Stone and The Dream of Red Mansion
}

\author{
Ting Wang ${ }^{1} \&$ Jiafeng Liu ${ }^{1}$ \\ ${ }^{1}$ School of Foreign Languages, Southwest University for Nationalities, Chengdu, China \\ Correspondence: Jiafeng Liu, School of Foreign Languages, Southwest University for Nationalities, Chengdu, \\ China.E-mail: 378411817@qq.com
}

Received: January 10, 2017 Accepted: February 3, 2017 Online Published: February 8, 2017

doi:10.5539/ells.v7n1p51 URL: http://dx.doi.org/10.5539/ells.v7n1p51

This paper is supported by the Fundamental Research Funds for the Central Universities, Southwest University for Nationalities (Grant No. CX2015SP153).

\begin{abstract}
The names of the characters in Hong Lou Meng, crafted to indicate both the development of the storyline and the characteristics of the characters, contain abundant culture-specific elements, which make them difficult to render into English. On the basis of a systematic study on the original work and its two unabridged translations of Hong Lou Meng, the culture-specific elements in the original names are categorized into the following three: Chinese naming, Chinese family hierarchy and Chinese Character. Three strategies on compensation for the lost culture-specific elements are found to be employed at different levels in the two translations, including on-line compensation, off-line compensation and zero compensation. The strategy of on-line compensation involves semantic translation plus transliteration and annotation in text. Off-line compensation includes note of Chinese spelling, annotation out of text, interpretation of characters' names in introduction, note ofcharacters' names in appendix, introduction of characters in appendix and dendrogram of genealogy; Zero compensation includes transliteration, omission, transfer, substitution and literal translation.
\end{abstract}

Keywords: culture-specific element, strategy, compensation, on-line compensation, off-line compensation, zero compensation

\section{Introduction}

As one of significant Chinese classical novels, Hong Lou Meng 红楼梦 has been translated into English, which has helped this work reach a broader audience in the English-speaking world. There are two well-known unabridged English translations of this novel. The first translation, entitled The Story of the Stone, is a projected five-volume translation work in progress by David Hawkes and John Minford (hereafter abbreviated as Hawkes \& Minford). The first three volumes are completed by David Hawkes, while the last two are finished by John Minford. The second, entitled The Dream of Red Mansion, was completed by Yang Xian-yi and Gladys Yang (hereafter abbreviated as the Yangs).

There are about 700 characters in Hong Lou Meng, whose names, crafted to indicate both the development of the storyline and the characteristics of the characters, contain abundant Chinese culture-specific elements, which make the names difficult to properly render into English. A lot of studies have been done on how to translate the names in the two unabridged translations (Xia, 2004, pp. 135-154; Tan, 2009; Liu, 2010, pp. 55-56; Lv \& Guan, 2011, pp. 263-270; Zhang, 2012; Zhang \& Cai, 2013, pp. 107-111). Few studies, however, have been made based on the Chinese culture-specific elements conveyed by the names of the characters in Hong Lou Meng systemically. Thus it is difficult to know whether the Chinese culture-specific elements are lost and whether compensation has been made or not and what strategies have been applied to compensate. In addition, although previous researches have analyzed what strategies have been employed to translate the names of the characters in two translated versions from the perspective of culture, they have shared the same opinion that The Story of the Stone is the product of domesticating, whereas The Dream of Red Mansion is the product of foreignizing generally (Liu, 2010, pp. 55-56; Lv \& Guan, 2011, pp. 263-270; Zhang, 2012.). These researches, however, haven't discussed the strategies on compensation for the lost Chinese culture-specific elements in translated 
names.As a result, a systematic analysis of Chinese culture-specific elements in the names is still lacking, and simply putting a label such as foreignization and domestication on the translations is rough, to a large extent. Therefore, this article analyzes the Chinese culture-specific elements in the original names of most characters and categorizes them into Chinese naming, Chinese family hierarchy and Chinese Character. Then this article explores the strategies for translating the names of most characters in the two translations to see whether the Chinese culture-specific elements are lost and what compensations have been made. This article attempts to make some contribution to the study of translation of the names of the characters in the process of introducing classic Chinese literature. Owing to great cultural difference between Chinese and English, Transliteration can not render the Chinese culture-specific elements in the names of the characters in Hong Lou Meng into English completely. That is to say, Chinese culture-specific elements in the original names are completely or partly lost.

To recapture what the writer intended to convey through the names, the translators of the two translations translated the names with strategies of direct in-text and indirect out-text compensation. To meet the potential readers' interests and to be easily memorized, translators excluded part of Chinese culture-specific elements conveyed by some names. To make these terms more vivid and easy to understand, the strategy of in-text compensation is called as strategy of "on-line" compensation; the strategy of out-text compensation is called as strategy of "off-line" compensation; and excluding strategy is called as strategy of zero compensation. Both "on-line" and "off-line" are computer terms originally. On-line refers to the state that a computer or a user is directly connected into a network and is capable of interacting with it (Ince, 2007, p. 169). Off-line is used to describe the state of a computer when it is disconnected from a network (Ince, 2007, p. 169). Strategy of on-line compensation: to avoid the loss of Chinese culture-specific elements in the original names, translators adopt proper translation methods to make a direct compensation in text, which includes semantic translation and annotation in text. Strategy of off-line compensation: because it is hard for translators to make compensation for the loss in text directly, translators compensate it out of the text with methods such as introduction of characters, dendrogram, interpretation of the names of the characters in introduction, annotation of the names of the characters in appendix and annotation of the names of the characters out of text. Strategy of zero compensation: translators omit the Chinese culture-specific elements in a name or just give up the compensation when transliteration fails to transmit the Chinese culture-specific elements.

\section{Chinese Culture-specific Elements in Names in Hong Lou Meng}

Hong Lou Meng has always been respected as "an encyclopedia of Chinese culture". There are about seven hundred characters with deep cultural connotations etched in their names. These names indicate the characteristics of the characters, imply the destinies and the family positions of the characters, and indicate the development of the storyline. It is not unnecessary to have a systematic analysis on the Chinese culture-specific elements of the names of most characters in Hong Lou Meng before the study on strategies employed to translate the names of most characters in the two unabridged translations.

\subsection{Chinese Naming}

Chinese, especially the ancients, attach great importance to names. According to Confucius, a great teacher and philosopher in the Spring and Autumn period of Chinese history, if names are not rectified, speech will not be justifiable. Su Dong-po, a prominent poet in the Song dynasty,claimed that name, the only thing, must not be insulted in the world; and Yan $\mathrm{Fu}$, a great Chinese scholar and translator in Qing dynasty, pointed out that establishing a good name maybe need several months.

Ancient Chinese people have different naming systems from that today. On the one hand, ancient Chinese people usually had school name, a formal given name under formal social occasion such as school where is the first formal social place for child (Chi, 2007, p. 28), and courtesy name, an informal name for daily communication, given when the male grow up to 20 years old and female grow up to 16 years old (Chi, 2007, p. 42). On the other hand, school name and courtesy name have an intertwined relationship. School names suggest the personalities, destinies or experiences of the characters while courtesy names are the supplement for school names.

There are plenty of good examples to illustrate what have put forward above in Hong Lou Meng. For instance, the school name of character, 贾瑞 (Jia Rui) is “瑞” (Rui), and his courtesy name is “天祥” (Tian-xiang). “瑞” means auspicious sign ( $\mathrm{Ci}$ Yuan, 2009, p. 2260). “天” points to the divinity, the master of all things (Ci Yuan, 2009, p. 748). “祥” refers to blessedness and auspiciousness (Ci Yuan, 2009, p. 2487). Therefore, “瑞” and “天 祥” have the same meaning that is positive and propitious.

\subsection{Chinese Family Hierarchy}

Most Chinese names not only have a referential meaning but indicate the person's position in the family 
hierarchy. As one of feudal families, the Jias also have a rigorous hierarchical system among males as well as females.

In chapter 53, when the Jias hold the ancestor worship ceremony, a strict system of family hierarchy is presented. “当时凡从文旁之名者, 贾敬为首; 下则从玉者, 贾珍为首; 在下从草头者, 贾蓉为首...” (Cao, 2008, p. 725). (the generations with radical, 文 (父) in given names is led by Jia Jing (贾敬), with radical 玉 (王) in given names is led by Jia Zhen (贾珍) and with radical 草 (+) in given names is led by Jia Rong (贾蓉)...) So the family hierarchies of males can be manifested by names in ancient China. There are four generations of female in Hong Lou Meng. To make these females' family hierarchies clear, Cao Xue-qin made great effort on names of characters in original work. Owing to the discrimination against the female in feudal society, the female of the Jias in Hong Lou Meng, like the females in real life, mostly have no normal names. That is to say, their names were not the structure, surname + given name, but surname + appellation and given name + appellation.

\subsection{Chinese Character}

The system of Chinese Character owns its unique mode of expression, mainly referring to the three-dimensional structure of sound, pattern and meaning. Due to the four-tone system in Chinese, there are a good deal of homophones and near-homophones. In Hong Lou Meng, homophones and near-homophones appear frequently in the names of the characters.

In Chinese, the character “贾” (one of surnames) and “假” (fake) have the same pronunciation, so does “雨” (rain) and “语” (words). Then the writer Cao Xue-qin points out that he will make up a story with 贾雨村言 (“贾雨” refers to fake words, so does “村言” in Chinese). Then it is natural to take “贾宝玉” (宝玉 means precious jade )as "fake jade".

Observing the pattern of Chinese characters, we can understand partial meaning of them. For example, 梧桐 (Chinese parasol tree). The two characters are combined by two parts respectively, “木 (wood) + 吾” (I) and “木 (wood) + 同” (the same). So it is easy for Chinese to deduce that the word, “梧桐”, refers to a kind of tree. In addition, to some extent, the pattern of Chinese Character is helpful in categorizing. In Chinese, the characters with “+” would be classified as herbs, like 花 (flower), 草 (grass).

To highlight the relationship among the three main characters, 贾宝玉 (Jia Bao-yu), 林黛玉 (Lin Dai-yu) and 薛宝钗(Xue Bao-chai), the author utilizes their names cleverly. “都道是金玉良缘, 俺只念木石前盟...” (Cao, 2008, p. 82). (it is said gold and jade will have a wonderful marriage, whereas I insist on the oath between wood and stone.) In the novel, this song implicated the relationship among the three characters. More importantly, the implication had a close relation with their names. The character “锞” is combined by “全” and “叉”. In Chinese, “全” means gold. Obviously, 宝玉 (Bao-yu)which means precious jade is the jade. While 贾 (jia) is the homophone for 假 (fake), so 贾宝玉 also can be understood as “fake jade and real stone”. The surname “林” of 林黛玉 is combined by two 木 (wood). Therefore, 薛宝钗 (Xue Bao-chai) refers to the gold in the prediction; 贾宝玉 (Jia Bao-yu), both jade and stone, and 林黛玉 (Lin Dai-yu), the wood.

Therefore, it is easily noticed that the names of characters in Hong Lou Meng must not be neglected. These names contain extensive Chinese traditional culture-specific elements. Hence, it is indispensable to attach importance to the culture-specific elements carried by the names of the characters in literature while translating, and if there is a loss of culture-specific elements, strategies of compensation are available.

\section{Strategies of Compensation in Two Translated Versions}

Due to the big differences between the Chinese naming culture and English naming culture, it is extremely difficult for translators to find out the equivalents to convey exact culture-specific elements in the names of the characters in Chinese novels. Then it's very crucial to get the right strategies to compensate the lost culture-specific elements in the names of the characters.

\subsection{Strategies on Compensation for the Lost Chinese Naming Elements}

Although there are numerous characters in Hong Lou Meng, it is countable for characters who have both school name and courtesy name. The strategies on compensation for the lost Chinese naming elements will be summarized through the table of the translation of school names and courtesy names. 
Table 1. Translation of school names and courtesy names

\begin{tabular}{|c|c|c|c|c|c|c|}
\hline & $\begin{array}{l}\text { Names of } \\
\text { characters }\end{array}$ & Frequency & $\begin{array}{l}\text { David Hawkes \& John } \\
\text { Minfest }\end{array}$ & Translation Method & $\begin{array}{l}\text { Yang Xianyi \& } \\
\text { Gladys Yang }\end{array}$ & Translation Method \\
\hline \multirow[t]{3}{*}{1} & 甄士隐 & --- & Zhen Shi-yin & $\begin{array}{l}\text { Transliteration } \\
+ \text { Space mark }\end{array}$ & Zhen Shiyin & Transliteration \\
\hline & School name:费 & 1 & Omitted & Omission & Fei & Transliteration \\
\hline & $\begin{array}{l}\text { Courtesy name: } \\
\text { 士隐 }\end{array}$ & 77 & Shi-yin & $\begin{array}{l}\text { Transliteration } \\
+ \text { Space mark }\end{array}$ & Shiyin & Transliteration \\
\hline \multirow[t]{3}{*}{2} & 林如海 & --- & Lin Ru-hai & $\begin{array}{l}\text { Transliteration } \\
+ \text { Space mark }\end{array}$ & Lin Ruhai & Transliteration \\
\hline & School name:海 & 1 & Omitted & Omission & Hai & Transliteration \\
\hline & $\begin{array}{l}\text { Courtesy name: } \\
\text { 如海 }\end{array}$ & 23 & Ru-hai & $\begin{array}{l}\text { Transliteration } \\
+ \text { Space mark }\end{array}$ & Ruhai & Transliteration \\
\hline \multirow[t]{3}{*}{3} & 贾赦 & --- & Jia She & Transliteration & Jia She & Transliteration \\
\hline & School name:赦 & 195 & She & Transliteration & She & Transliteration \\
\hline & $\begin{array}{l}\text { Courtesy name: } \\
\text { 恩侯 }\end{array}$ & 1 & Omitted & Omission & Enhou & Transliteration \\
\hline \multirow[t]{4}{*}{4} & 贾政 & --- & Jia Zhen & Transliteration & Jia Zhen & Transliteration \\
\hline & School name:政 & 946 & Zhen & Transliteration & Zhen & Transliteration \\
\hline & $\begin{array}{l}\text { Courtesy name: } \\
\text { 存周 }\end{array}$ & 3 & $\begin{array}{l}\text { 1) Appearing in text firstly, } \\
\text { omitted }\end{array}$ & Omission & $\begin{array}{l}\text { 1)Appearing firstly, } \\
\text { translated into } \\
\text { Cunzhou }\end{array}$ & Transliteration \\
\hline & & & $\begin{array}{l}\text { 2) Appearing in chapter, } \\
\text { translated into Jia Zheng }\end{array}$ & $\begin{array}{l}\text { School name } \\
\text { substitutes } \\
\text { courtesy name }\end{array}$ & $\begin{array}{l}\text { 2) Appearing in } \\
\text { chapter, translated into } \\
\text { Jia Zheng }\end{array}$ & $\begin{array}{l}\text { School name } \\
\text { substitutes } \\
\text { courtesy name }\end{array}$ \\
\hline \multirow[t]{4}{*}{5} & 薛蟠 & --- & Xue Pan & Transliteration & Xue Pan & Transliteration \\
\hline & School name:蟠 & 285 & Pan & Transliteration & Pan & Transliteration \\
\hline & $\begin{array}{l}\text { Courtesy name: } \\
\text { 文龙 }\end{array}$ & 2 & $\begin{array}{l}\text { 1) Appearing in text firstly, } \\
\text { omitted }\end{array}$ & Omission & $\begin{array}{l}\text { 1) Appearing firstly, } \\
\text { translated into } \\
\text { Wenlong }\end{array}$ & Transliteration \\
\hline & & & $\begin{array}{l}\text { 2) Appearing in chapter, } \\
\text { translated into Xue Pan }\end{array}$ & $\begin{array}{l}\text { School name } \\
\text { substitutes } \\
\text { courtesy name }\end{array}$ & $\begin{array}{l}\text { 2) Appearing in } \\
\text { chapter, translated into } \\
\text { Xue Pan }\end{array}$ & $\begin{array}{l}\text { School name } \\
\text { substitutes courtesy } \\
\text { name }\end{array}$ \\
\hline \multirow[t]{4}{*}{6} & 秦钟 & --- & Qin Zhong & Transliteration & Qin Zhong & Transliteration \\
\hline & School name:钟 & 107 & Zhong & Transliteration & Zhong & Transliteration \\
\hline & $\begin{array}{l}\text { Courtesy name: } \\
\text { 鲸卿 }\end{array}$ & 3 & $\begin{array}{l}\text { 1) Appearing firstly, } \\
\text { translated into "Jing-qing" } \\
\text { (which was his } \\
\text { school-name) }\end{array}$ & $\begin{array}{l}\text { Transliteration } \\
\text { +Space mark } \\
\text { + annotation } \\
\text { in text }\end{array}$ & $\begin{array}{l}\text { 1) Appearing firstly, } \\
\text { translated into } \\
\text { courtesy name }\end{array}$ & $\begin{array}{l}\text { School name } \\
\text { substitutes courtesy } \\
\text { name }\end{array}$ \\
\hline & & & $\begin{array}{l}\text { 2) Appearing in chapter, } \\
\text { translated into Qin Zhong }\end{array}$ & $\begin{array}{l}\text { School name } \\
\text { substitutes } \\
\text { courtesy name }\end{array}$ & $\begin{array}{l}\text { 2) Appearing in } \\
\text { chapter, translated into } \\
\text { Qin Zhong }\end{array}$ & $\begin{array}{l}\text { School name } \\
\text { substitutes courtesy } \\
\text { name }\end{array}$ \\
\hline \multirow[t]{3}{*}{7} & 贾瑞 & --- & Jia Rui & Transliteration & Jia Rui & Transliteration \\
\hline & School name:瑞 & 73 & Rui & Transliteration & Rui & Transliteration \\
\hline & $\begin{array}{l}\text { Courtesy name: } \\
\text { 天祥 }\end{array}$ & 1 & $\begin{array}{l}\text { Appearing in chapter, } \\
\text { translated into Jia Rui }\end{array}$ & $\begin{array}{l}\text { School name } \\
\text { substitutes } \\
\text { courtesy name } \\
\end{array}$ & $\begin{array}{l}\text { Appearing in chapter, } \\
\text { translated into Jia Rui }\end{array}$ & $\begin{array}{l}\text { School name } \\
\text { substitutes courtesy } \\
\text { name }\end{array}$ \\
\hline \multirow[t]{4}{*}{8} & 李纳 & --- & Pinyin & Transliteration & Li Wan & Transliteration \\
\hline & School name:纨 & 368 & $\begin{array}{l}\text { Wan (which means a kind } \\
\text { of silk, was intended to } \\
\text { symbolize her dedication to } \\
\text { the needle.) }\end{array}$ & $\begin{array}{l}\text { d Transliteration } \\
0+\text { annotation in text } \\
0\end{array}$ & $\begin{array}{l}\text { Wan } \\
\text { (Plain Silk) }\end{array}$ & $\begin{array}{l}\text { Transliteration }+ \\
\text { annotation out of text }\end{array}$ \\
\hline & $\begin{array}{l}\text { Courtesy name: } \\
\text { 宫裁 }\end{array}$ & $: 19$ & Omitted & Omission & $\begin{array}{l}\text { Gongcai } \\
\text { (Palace Seamstress) }\end{array}$ & $\begin{array}{l}\text { Transliteration }+ \\
\text { annotation out of text }\end{array}$ \\
\hline & & & $\begin{array}{l}\text { Li Wan } \\
\text { (all the } \\
\text { inhabitants) }\end{array}$ & $\begin{array}{l}\text { School name substitut } \\
\text { s courtesy name }\end{array}$ & $\begin{array}{l}\text { Si Wan } \\
\text { (His widow) }\end{array}$ & $\begin{array}{l}\text { School name } \\
\text { substitutes } \\
\text { courtesy name }\end{array}$ \\
\hline
\end{tabular}


In table 1 , it is obvious that there are differences and similarities between the two unabridged translations in treating characters' school names and courtesy names.

\subsubsection{Strategies on Compensation for the Lost Chinese Naming Elements in The Story of the Stone}

When it comes to the strategies on compensation for the lost Chinese naming elements in The Story of the Stone, it can be summarized that Hawkes \& Minford employ the strategies of on-line compensation, off-line compensation and zero compensation. These three strategies are realized by the following four translation methods. That is, transliteration (plus space mark), omission, school name substituting courtesy name and transliteration plus annotation within text. Transliteration, refers to the translation with Chinese phonetic alphabet. Fang Meng-zhi defines omission as "to omit the words that are not essential or clumsy or the words that are incompatible with English-language custom" (Fang, 2011, p. 116). In this article, however, omission means that translators choose some elements in original work and ignore them on purpose. Substitution means that pro-forms are used to replace the existing words (Fang, 2011, p. 117). In this article, substitution refers to the way of using referential words, but not pro-forms, to replace another one. In English, solanum tuberosum and potato are the same one. Solanum tuberosum from Latin is the scientific name while potato is the common name. In Chinese, Solanum tuberosum and potato correspond to “马铃薯” and “土豆” respectively. So the phenomenon that Solanum tuberosum is rendered into “土豆” is regarded as substitution. "Annotation" refers to a note by way of explanation or comment added to a text or diagram (The New Oxford Dictionary, 2007, p. 76). And according to position, annotation is classified into annotation in text and annotation out of text in this article.

Taking 贾赦 (Jia She) as example, his school name is “赦” (She) which means remitting a punishment (Ci Yuan, 2009, p. 3252), and his courtesy name is “恩侯” (En-hou). “恩” means grace. (Ci Yuan, 2009, p. 1227), and “侯” refers to the second rank of ancient five ranks of nobility-Public, Hou, Peter, Son and Male (Ci Yuan, 2009, p. 235). So the combination means that because of the grace given by emperor, Jia She wins himself the second rank of nobility. Thus, the courtesy name has the same reference as the school name.

When disposing the courtesy name, Hawkes \& Minford omit it at the first time. Then they substitute school names for all courtesy names appearing in the following text. To put it simply, whether by omitting or substituting, the Chinese culture-specific meaning of this courtesy name is lost. More importantly, the close relation between school name and courtesy name are neglected. Hawkes \& Minford resort to the method, transliteration plus annotation in text, to handle Li Wan's school name 纨 (Wan). But the courtesy name of this character is omitted, too.

....and even her name "Wan", which means a kind of silk, was intended to symbolize her dedication to the needle (Hawkes, Volume I, p. 108).

With the translation methods of omission, substitution and annotation in text, Hawkes \& Minford employ the strategies of zero compensation and on-line compensation to preserve the school name's referential meaning and exotic style as well as convey the Chinese culture-specific meaning. Although transliteration plays a referential function and maintains exotic sense, it could not make any compensation for school name's connotative meaning. Adopting the methods of omission and substitution, Hawkes \& Minford neglect the Chinese culture-specific elements in the courtesy name totally. To relive the culture-specific elements in the names of the characters, Hawkes \& Minford make good use of the strategies of on-line compensation and zero compensation. That is, they put on-line compensation into action by transliteration plus annotation in text. By omission and substitution, zero compensation is put into action.

\subsubsection{Strategies on Compensation for the Lost Chinese Naming Elements in The Dream of Red Mansions}

When it comes to strategies on compensation for the lost Chinese naming elements in The Dream of Red Mansions, The Yangs also employ the strategies of on-line compensation, off-line compensation and zero compensation at different levels. These three strategies are realized by the following three translation methods. That is, transliteration, school name substituting courtesy name and transliteration plus annotation out of text.

Like Hawkes \& Minford, the Yangs also treat the school names of the characters with transliteration. When dealing with courtesy names, the couple choose a translation method different from that of Hawkes \& Minford. When the names of the characters appear at the first time, translators translate them by transliteration. But in the following text, translators use the school names to replace all courtesy names of the characters. By translating the courtesy names with transliteration, translators remind English-speaking readers of the co-exist of school name and courtesy name in Chinese naming system. While substituting school names for courtesy names weakens the role of courtesy names in Chinese naming system to a large extent. The Yangs employ the strategy of off-line 
compensation to treat the name of 李纨 (Li Wan) with transliteration plus notes of the names of character, when her school name and courtesy name appear at the first time. This strategy not only preserves the school name's referential meaning and exotic sense, but accounts for its connotative meaning.

To interpret the figures and personalities of the characters and introduce ancient Chinese naming culture, the couple translators adopt annotations in appendix as one method of the strategy of off-line compensation and substitution and omission as two methods of the strategy of zero compensation.

In short, the translators of the two translated versions adopt three strategies at different levels. Hawkes \& Minford employs the strategy of on-line compensation with the translation method of annotation in text and the strategy of zero compensation with substitution and omission. The Yangs employ the strategy of off-line compensation the translation method of annotation out of text and the strategy of zero compensation with the translation methods of substitution and omission.

\subsection{Strategies on Compensation for the Lost Chinese Family Hierarchy Elements in Names}

According to cultural linguistics, the emphasis on clan and hierarchy in Chinese patriarchal ethics has a great influence on the ways of naming. In ancient times, there was a common principle in Chinese Han nationality: people with the same positions in the family hierarchy must share a character or radical in their names (Zhang, 2010 , p. 73). In addition, the appellation for women was a way to reveal their positional difference. Therefore, the family position of character can be distinguished by his or her name. But how to convey the family position of characters in English is a real challenge. Therefore, strategies on compensation for the lost Chinese family hierarchy elements in the names of the characters will be discussed in detail.

\subsubsection{Strategies on Compensation for the Lost Chinese Family Hierarchy Elements Inmale Names}

As far as the strategies on compensation for the lost Chinese family hierarchy elements in male names are concerned, through the analysis of the translation methods used in the two translated versions, it can also be summarized that strategies of on-line compensation, off-line compensation and zero compensation are adopted at different levels in the two translations. However, Hawkes \& Minford and the Yangs realize the three strategies with different translation methods.

In the original Chinese novel, the relationship of family hierarchy among male characters is presented mainly by the characters and radicals in the names of male characters in Hong Lou Meng (table 2).

Table 2. Family hierarchy of male characters

\begin{tabular}{lll}
\hline & Names of male characters & Characters or radicals \\
\hline The first generation & 贾代善、贾代化、贾代儒... & 代 (Character) \\
The second generation & 贾赦, 贾敬、贾政... & 女 (radical) \\
The third generation & 贾珍、贾琏、贾环... & 王 (radical) \\
The fourth generation & 贾蓉、贾兰 (蘭)... & \# (radical) \\
\hline
\end{tabular}

There are four generations of the Jias' men in Hong Lou Meng. The first generation have the character一代 in their names. The second, third and fourth generations have the radicals 女, 王 and \# in their names respectively. In Chinese, radical 父 means 文 (sounds like Wen, means language); radical 王 refers to 玉 (sounds like Yu, means jade); and radical \# points to 草 (sounds like Cao, means grass).

Both Hawkes \& Minford and the Yangs utilize transliteration to translate the names of those male characters mentioned above. But Hawkes \& Minford uses space mark to distinguish two characters in given names. Unfortunately, transliteration can not convey the Chinese culture-specific elements carried by Chinese characters and radicals in names. So Hawkes \& Minford remedy this problem by adopting off-line compensation. First, they add a section entitled "Characters in Volume", to provide a brief background sketch for every character in Hong Lou Meng. Second, they make use of dendrogram to illustrate the family relationship among the Jias. In the dendrogram, however, only part of the characters are introduced. The Yangs employ dendrogram, too. Similarly, the family hierarchies of some male characters are compensated.

Case 1. 且说他姑妈原嫁给了贾家“玉”字辈的嫡派, 名唤贾璜 (Cao, 2000, p. 72). (His paternal aunt had married Jia Huang (贾璜), who belongs to the generation of “jade” (玉) in the Jias.)

Jokey Jin's aunt was married to one Jia Huang, a member of the Jia clan in the same generation as Jia Zhen and Jia Lian. (Hawkes, Volume I, p. 218) 
Now Jin Rong's paternal aunt had married Jia Huang of that generation of the family which used the "jade" ( $y u)$ radical. (Yang \& Yang, Volume I, p. 192)

In case 1, Cao Xueqin points out clearly that 贾璜 (Jia Huang) is the generation of 玉 (jade). As analyzed above, the radical “王” means 玉 (jade) in Chinese. So it is easy for Chinese readers to comprehend.

Hawkes \& Minford utilize the method of transfer to deal with this part. 贾璜 (Jia Huang) was parallel to other main characters, 贾珍 (Jia Zhen) and 贾琏 (Jia Lian) to illustrate the family hierarchy of 贾璜 indirectly. Transfer refers to the way that when it is impossible to represent the content with the same way as that in the original language, translator would choose anther way to make it. (Fang, 2011, p. 114) Although Hawkes makes it clear that 贾璜 is the same generation as 贾珍 (Jia Zhen) and 贾琏 (Jia Lian), the family hierarchies of the characters reflected by names are lost.

The Yangs use semantic translation, a method to realize on-line compensation, to interpret why 贾璜 (Jia Huang) is the generation of "jade" directly and account for character's family hierarchy contained in his name clearly.

Case 2. 当时凡从文旁之名者, 贾敬为首; 下则从玉者, 贾珍为首; 再下从草头者, 贾蓉为首 (Cao, 2000, p. 409). (The generation whose given names contain the radical 女 (文) is leaded by Jia Jing (贾敬); the generation whose given names contain the radical 王 (玉) is leaded by Jia Zhen (贾珍) and the generation whose given names contain the radical \# (草) is leaded by Jia Rong (贾蓉).)

Places were assigned according to generations, Jia Jing heading the senior group, Jia Zhen the second, and Jia Rong the third. (Yang \& Yang, Volume I, 2012, p. 1086)

When coming to case 2, Hawkes \& Minford adopt the strategy of zero compensation through omission. In another word, the Chinese family hierarchy element in the original name is lost and the translators don't take any action to compensate.

While the Yangs transfer the intended meaning of the name in their translation with ordinal numeral (the senior, the second and the third) to distinguish the generations, the Chinese family hierarchy element in the name is lost. Accordingly, transfer is regarded as a kind of on-line compensation.

All in all, when dealing with Chinese family hierarchy reflected in male names, both Hawkes \& Minford and the Yangs choose the strategies of on-line compensation, off-line compensation and zero compensation at different levels. To put on-line compensation into effect, the Yangs resort to semantic translation. With the guidance of off-line compensation, Hawkes \& Minford introduce characters appearing in each volume and provides dendrograms. The Yangs adopt dendrogram, too. Hawkes and the Yangs take advantage of zero compensation with omission and on-line compensation with transfer.

\subsubsection{Strategies on Compensation for the Lost Chinese Family Hierarchy Elements Infemale Names}

In the original novel, the names of female characters also reveal their family hierarchies. Hence, when render these female names into English, Hawkes \& Minford and the Yangs adopt the strategies of on-line compensation and zero compensation at different levels respectively. And these two strategies are realized by the translation methods summarized in table 3, which shows there are some differences between the translation methods employed in the two translations. Hawkes \& Minford adopt the strategy of on-line compensation with semantic translation plus transliteration as well as the strategy of zero compensation with transliteration plus space mark. The Yangs adopt the strategy of on-line compensation with semantic translation, semantic translation plus transliteration as well as the strategy of zero compensation with transliteration. 
Table 3. Translation of names of some female characters in Hong Lou Meng

\begin{tabular}{|c|c|c|c|c|c|c|c|c|}
\hline & $\begin{array}{l}\text { Names } \\
\text { of } \\
\text { characters }\end{array}$ & $\begin{array}{l}\text { Name } \\
\text { structure }\end{array}$ & $\begin{array}{l}\text { David } \\
\text { Hawkes \& } \\
\text { John Minford } \\
\end{array}$ & $\begin{array}{l}\text { Translation } \\
\text { structure }\end{array}$ & $\begin{array}{l}\text { Translation } \\
\text { method }\end{array}$ & $\begin{array}{l}\text { Yang Xianyi \& } \\
\text { Gladys Yang }\end{array}$ & $\begin{array}{l}\text { Translation } \\
\text { structure }\end{array}$ & $\begin{array}{l}\text { Translation } \\
\text { method }\end{array}$ \\
\hline \multirow[t]{2}{*}{1} & 贾母 & $\begin{array}{l}\text { Husband's } \\
\text { surname }+ \\
\text { appellation }\end{array}$ & $\begin{array}{l}\text { Old Lady Jia / } \\
\text { Grandmother } \\
\text { Jia }\end{array}$ & $\begin{array}{l}\text { Old+appellation } \\
\text { + husband's } \\
\text { surname / } \\
\text { Appellation + } \\
\text { husband's } \\
\text { surname }\end{array}$ & $\begin{array}{l}\text { semantic } \\
\text { translation }+ \\
\text { transliteration }\end{array}$ & $\begin{array}{l}\text { The Lady } \\
\text { Dowager/Her/ } \\
\text { his grandmother; }\end{array}$ & $\begin{array}{l}\text { Appellation } \\
\text { / Her/his } \\
+ \\
\text { appellation }\end{array}$ & $\begin{array}{l}\text { semantic } \\
\text { translation }\end{array}$ \\
\hline & 史太君 & $\begin{array}{l}\text { Surname }+ \\
\text { appellation }\end{array}$ & Lady Jia & $\begin{array}{l}\text { Appellation + } \\
\text { husband's } \\
\text { surname }\end{array}$ & $\begin{array}{l}\text { semantic } \\
\text { translation }+ \\
\text { transliteration }\end{array}$ & $\begin{array}{l}\text { The Lady } \\
\text { Dowager }\end{array}$ & Appellation & $\begin{array}{l}\text { semantic } \\
\text { translation }\end{array}$ \\
\hline \multirow[t]{5}{*}{2} & 王夫人 & $\begin{array}{l}\text { Surname }+ \\
\text { appellation }\end{array}$ & Lady Wang & $\begin{array}{l}\text { Appellation } \\
+ \text { surname }\end{array}$ & $\begin{array}{l}\text { semantic } \\
\text { translation }+ \\
\text { transliteration }\end{array}$ & Lady Wang & $\begin{array}{l}\text { Appellation } \\
+ \text { surname }\end{array}$ & $\begin{array}{l}\text { semantic } \\
\text { translation }+ \\
\text { transliteration }\end{array}$ \\
\hline & 邢夫人 & $\begin{array}{l}\text { Surname }+ \\
\text { appellation }\end{array}$ & Lady Xing & $\begin{array}{l}\text { Appellation } \\
+ \text { surname }\end{array}$ & $\begin{array}{l}\text { semantic } \\
\text { translation+ } \\
\text { transliteration }\end{array}$ & Lady Xing & $\begin{array}{l}\text { Appellation } \\
+ \text { surname }\end{array}$ & $\begin{array}{l}\text { semantic } \\
\text { translation }+ \\
\text { transliteration }\end{array}$ \\
\hline & 赵姨娘 & $\begin{array}{l}\text { Surname }+ \\
\text { appellation }\end{array}$ & Aunt Zhao & $\begin{array}{l}\text { Appellation } \\
+ \text { surname }\end{array}$ & $\begin{array}{l}\text { Semantic } \\
\text { translation }+ \\
\text { transliteration }\end{array}$ & $\begin{array}{l}\text { Concubine } \\
\text { Zhao、 }\end{array}$ & $\begin{array}{l}\text { Appellation } \\
+ \text { surname }\end{array}$ & $\begin{array}{l}\text { semantic } \\
\text { translation }+ \\
\text { transliteration }\end{array}$ \\
\hline & 周姨娘 & $\begin{array}{l}\text { Surname }+ \\
\text { appellation }\end{array}$ & Aunt Zhou & $\begin{array}{l}\text { Appellation } \\
+ \text { surname }\end{array}$ & $\begin{array}{l}\text { semantic } \\
\text { translation }+ \\
\text { transliteration }\end{array}$ & Concubine Zhou & $\begin{array}{l}\text { Appellation } \\
+ \text { surname }\end{array}$ & $\begin{array}{l}\text { semantic } \\
\text { translation }+ \\
\text { transliteration }\end{array}$ \\
\hline & 薛姨妈 & $\begin{array}{l}\text { Husband's } \\
\text { surname + } \\
\text { appellation }\end{array}$ & Aunt Xue & $\begin{array}{l}\text { Appellation } \\
+ \text { surname }\end{array}$ & $\begin{array}{l}\text { Semantic } \\
\text { translation }+ \\
\text { transliteration } \\
\end{array}$ & Aunt Xue & $\begin{array}{l}\text { Appellation } \\
+ \text { surname }\end{array}$ & $\begin{array}{l}\text { semantic } \\
\text { translation }+ \\
\text { transliteration }\end{array}$ \\
\hline \multirow[t]{2}{*}{3} & 尤氏 & $\begin{array}{l}\text { surname }+ \\
\text { appellation }\end{array}$ & You-shi & Given name & $\begin{array}{l}\text { transliteration } \\
+ \text { space mark }\end{array}$ & Madam You & $\begin{array}{l}\text { Appellation } \\
+ \text { surname }\end{array}$ & $\begin{array}{l}\text { Semantic } \\
\text { translation }+ \\
\text { transliteration }\end{array}$ \\
\hline & $\begin{array}{l}\text { 林黛玉, } \\
\text { 薛宝钗... }\end{array}$ & $\begin{array}{l}\text { Surname + } \\
\text { given } \\
\text { name }\end{array}$ & $\begin{array}{l}\text { Lin Dai-yu, } \\
\text { Xie Bao-chai }\end{array}$ & $\begin{array}{l}\text { Surname }+ \\
\text { given name }\end{array}$ & $\begin{array}{l}\text { transliteration } \\
+ \text { space mark }\end{array}$ & $\begin{array}{l}\text { Lin Daiyu, } \\
\text { Xie Baochai }\end{array}$ & $\begin{array}{l}\text { Surname + } \\
\text { given name }\end{array}$ & transliteration \\
\hline \multirow[t]{3}{*}{4} & 秦氏 & $\begin{array}{l}\text { Surname }+ \\
\text { appellation }\end{array}$ & Qin-shi & Given name & $\begin{array}{l}\text { transliteration } \\
+ \text { space mark }\end{array}$ & Qin Ke-qing & $\begin{array}{l}\text { Surname + } \\
\text { given name }\end{array}$ & transliteration \\
\hline & 胡氏 & $\begin{array}{l}\text { Surname }+ \\
\text { appellation }\end{array}$ & Hu-shi & Given name & $\begin{array}{l}\text { transliteration } \\
+ \text { space mark }\end{array}$ & Madam $\mathrm{Hu}$ & $\begin{array}{l}\text { Appellation } \\
+ \text { surname }\end{array}$ & $\begin{array}{l}\text { semantic } \\
\text { translation+ } \\
\text { transliteration }\end{array}$ \\
\hline & 巧姐 & $\begin{array}{l}\text { Given } \\
\text { name }+ \\
\text { appellation }\end{array}$ & Qiao-jie & Given name & $\begin{array}{l}\text { transliteration } \\
+ \text { space mark }\end{array}$ & Qiaojie & $\begin{array}{l}\text { Given name } \\
\text { +appellation }\end{array}$ & transliteration \\
\hline
\end{tabular}

In table 3, there are four generations. The first generation is called "X 母" or "X 太君”; the second one is called “X人”, “ $X$ 姨娘” and “X 姨妈”; the third one includes the married women who are called "X 氏” and the unmarried who hold surnames and given names; the fourth one also involves the married women who are called “X 氏” and the unmarried called “X 姐”. “母” $(\mathrm{Mu})$ refers to the senior woman in a Chinese big family, and “太君” is a title for a woman conferred upon by the emperor. “夫人” is a title for the wife or mother of officer given by the emperor. In Chinese feudal society, the concubine is called “姨娘”. Sisters of mother are called “姨 妈”. “氏” is a courteous appellation for married woman. (http://baike. haosou.com) “姐”, used in name in Song dynasty, originally refers to the older sister in Chinese. Usually, it is used to call a child to show the feeling of love. (Qi, 2007, pp. 223-238) There are some female characters in the third generation who hold their surnames and given names. By this way, these female characters have been highlighted as main characters and it is favorable for distinguishing their family hierarchies.

\subsubsection{Strategies on Compensation for the Lost Chinese Family Hierarchy Elements in Female Names in The} Story of The Stone

Hawkes \& Minford employ the strategies of on-line compensation and zero compensation with transliteration plus semantic translation and transliteration (plus space mark) to deal with those female names. Firstly, to deal with the name structure of "surname" + "appellation", Hawkes \& Minford adopt "transliteration" + "semantic translation" and switch the order. For example, “王夫人” is translated into "Lady Wang". Then to handle the name structures-“surname" + “氏”, "surname” + "given name” and "given name” + “姐”, Hawkes \& Minford 
only adopt transliteration (plus space mark).

The two translation methods Hawkes \& Minford utilize can help readers to identify three generations. Firstly, “母” and “夫人” are translated into "Old lady" and "lady" respectively. The word "old" distinguishes the two generations cleverly and directly. But when translating “姨娘” and “姨妈”, Hawkes \& Minford didn’t realize the difference between the two appellations and translated them into "aunt". "Aunt" in English is used to call the sister of one's father or mother or the wife of one's uncle. (The New Oxford Dictionary, 2007, p. 126) it is not used to call father's concubines. Hawkes \& Minford did retain the last names of a handful of female characters with transliteration (plus space mark), keeping the name structures- "surname" + “氏", "surname" + "given name" and "given name" + “姐”. The appellations, “氏” and “姐”, have their specific meaning in Chinese as analyzed above. Transliteration can lead English-speaking readers to have a misunderstanding. For example, Hawkes \& Minford translated “尤氏” and “巧姐” into "You-shi" and "Qiao-jie" respectively. On the one hand, English-speaking readers will misunderstand "You-shi" and "Qiao-jie" as given names. On the other hand, “氏” and "姐” will lose their family hierarchy elements of the female characters in Hong Lou Meng. Compared with the clear distinction among four generations carried by the names in original novel, the methods Hawkes \& Minford took have made partial compensation for the family hierarchy elements presented by the names of female characters.

3.2.2.2 Strategies on Compensation for the Lost Chinese Family Hierarchy Elements Infemale Names in The Dream of Red Mansion

The Yangs also employ the strategy of on-line compensation. However, the strategy of on-line compensation in The Dream of Red Mansion involves semantic translation and transliteration plus semantic translation. Firstly, to deal with the name structure of "surname" + "appellation", Hawkes \& Minford adopt "transliteration" + "semantic translation" and switch the order. For example, “王夫人” is translated into "Lady Wang". Then to handle the name structures-"surname" + "氏", "surname" + "given name" and "given name" + “姐”, Hawkes $\&$ Minford only adopt transliteration (plus space mark). Semantic translation emphasizes meaning, not other subtleties, such as syntactic structure, wording and metaphor and so on. (Fan, 1994, p. 91)

The Yangs take advantage of semantic translation to deal with “贾母” who is the highest ranking woman in the Jias. The translation "Lady Dowager" is easy for English-speaking readers to know the supreme position of 贾 母 in the Jias. Such a method has accomplished the strategy of on-line compensation and made a sufficient compensation. Furthermore, to render the name structure, "surname” + “appellation” (夫人，姨妈，姨娘，氏) into English, the Yangs applied the method "transliteration" + "semantic translation" and switch the order(except “秦氏”). They rendered “夫人” into “lady”, “姨娘” into “Concubine”, “姨妈” into “Aunt” and “氏” into "Madam". This strategy of on-line compensation made up clearly.

In addition, the Yangs utilized transliteration to handle the name structures, "surname" + "given name" and "given name" + "appellation" (姐). Translating the structure- "surname" + "given name" by transliteration is helpful in stressing these main female characters' importance. But transliteration can not transmit the profound meaning of “姐” in Chinese naming system and can not present the character's family hierarchy.

To sum up, the strategy of on-line compensation is adopted by both Hawkes \& Minford and the Yangs to dispose family hierarchy elements carried by the names of characters. Semantic translation and transliteration plus semantic translation have done a great favor for this strategy. Yet the appellations, like “氏” and “姐”, were rendered into English felicitously.

\subsection{Strategies on Compensation for the Lost Chinese Character Elements in Names}

In the original novel, Cao Xueqin utilized the three-dimensional structure of sound, pattern and meaning of Chinese Character tactfully. In English, there are homophones and near-homophones. Nonetheless, it is hardly possible to find the equivalent for the homophones in Chinese opportunely. In English, affix is a vital role in expressing meaning. Compared with the radical of Chinese Character, however, affix has a limited practice. Then how to render the three-dimensional structure in the names of characters into English is also a great challenge. So strategies on compensation for the lost Chinese character elements in the names of characters will be discussed in the following.

\subsubsection{Strategies on Compensation for the Lost Sound of Chinese Character}

In Chinese, on account of the four-tone system, homophones and near-homophones are ubiquitous. Thus, it is conductive for Chinese writers to take advantage of them to state their subtle intention. In Hong Lou Meng, the sounds of names of the characters are also a key to understand the writers' implication. As to the strategies on compensation for the lost sound of Chinese character, it can be summarized that strategies of off-line 
compensation and zero compensation are employed at different levels in the two translations. To realize the two strategies, Hawkes \& Minford adopt four methods, including interpretation of names of characters in introduction, literal translation plus annotation out of text, transliteration (plus space mark) and omission. The Yangs use transliteration plus annotation out of text, transliteration and literal translation.

Table 4. Translation of names of two characters with homophones and near-homophones elements

\begin{tabular}{|c|c|c|c|c|c|c|}
\hline Number & $\begin{array}{l}\text { Names of } \\
\text { characters }\end{array}$ & homophone & David Hawkes & Translation method & Yang Xian-yi \& Gladys Yang & Translation method \\
\hline 1 & 贾雨村 & $\begin{array}{l}\text { 假语村 (言) } \\
\text { (fake words) }\end{array}$ & Jia Yu-cun & $\begin{array}{l}\text { transliteration }+ \\
\text { space mark }\end{array}$ & $\begin{array}{l}\text { Jia Yucun (Homophone for } \\
\text { "fiction in rustic language") }\end{array}$ & $\begin{array}{l}\text { transliteration }+ \\
\text { annotation out of text }\end{array}$ \\
\hline 2 & 甄士隐 & $\begin{array}{l}\text { 真事隐 } \\
\text { (concealing truth) }\end{array}$ & Zhen Shi-yin & $\begin{array}{l}\text { transliteration }+ \\
\text { space mark }\end{array}$ & $\begin{array}{l}\text { Zhen Shiyin (Homophone for } \\
\text { "true facts concealed") }\end{array}$ & $\begin{array}{l}\text { Transliteration }+ \\
\text { annotation out of text }\end{array}$ \\
\hline
\end{tabular}

“假作真时真亦假, 无为有时有还无” (Cao, 2008, p. 10) (taking the fake as real for a long time, the real would be fake eventually; taking nothing as everything for a long time, everything would be nothing eventually.), this couplet is a significant clue in Hong Lou Meng. Cao Xueqin hid this thought in the surnames “贾” and “甄”, the homophones for “假” (fake) and “真” (real) respectively. Hawkes \& Minford used transliteration to translate the surnames (see table 4). Because “Jia" (贾) and “Zhen" (甄) have no essential meaning, except the referential function in English. The Chinese phonetic alphabet of the two surnames can not transmit the effect of homophone. To compensate for the loss, Hawkes \& Minford resorted the strategy of off-line compensation. In introduction, they stated the relation between the surnames and their homophones as follows:

One he makes persistent use of throughout the novel is the antinomy of zhen and Jia, meaning respectively "real" and "imaginary"... (Hawkes, Volume I, 1973, p. 44).

"Jia"...but it is also a pun on this other jia which means "fictitious" (Hawkes, Volume I, 1973, p. 44).

In addition, making good use of homophones, Cao Xueqin named a pair of Characters especially—甄士隐 (Zhen Shi-yin) and 贾雨村 (Jia Yu-cun). Hong Long Meng started with the story of the two characters and ended with their story. So the two characters are significant. As described in Chapter 1, Cao Xueqin concealed the true facts (真事隐去) and made up a story (假语村言). 真事隐 (conceal the true facts) and 假语村 (fake words) are the homophones for names一甄士隐 and 贾雨村 respectively. Hawkes \& Minford translated the two names by transliteration plus space mark (see table 5), and when coming to the elements about the two names in chapter 1, Hawkes \& Minford omitted this part. Although transliteration has referential meaning and saves the exotic sense, it can not transmit the meaning of homophone in Chinese. Facing the special meaning of “甄士隐” and “贾雨村”, Hawkes \& Minford adopted the strategy of zero compensation, omitting the culture-specific elements.

To compensate the lost sound of Chinese character, the Yangs adopt the strategy of off-line compensation with transliteration plus annotation out of text, explaining the connotative meaning of the two names caused by their homophones in the part of "Notes", as following:

(Zhen Shiyin is the) Homophone for "true facts concealed"

(Jia Yucun is the) Homophone for "fiction in rustic language" (Yang \& Yang, Volume I, 2012, p. 645)

Furthermore, “玉带林中挂, 金䙃雪里埋” (Cao Xueqin, 76) (the belt of jade is hanging on the tree, while the golden hairpin is buried in the snow.), this prediction of the two main females, 林黛玉 (Lin Dai-yu) and 薛宝 钗 (Xue Bao-chai) took sufficiently advantage of the homophone in Chinese. Switched the order of the three characters-“玉带林” (yu-dai-lin), they sound like “林黛玉” (Lin Dai-yu). And the character “雪” (xue) sounds like “薛” (xue), the surname of 薛宝钗.

To deal with this prediction, Hawkes \& Minford resort to the strategy of off-line compensation, achieved by literal translation plus annotation out of text. According to Baker, literal translation is ideally the segmentation of the SL text into individual words and TL rendering of those word-segments one at a time. So here, literal translation just interprets the literal meaning of the prediction, but can not reveal the fact that the names of the two main females are hidden in the prediction. Therefore, it is not easy for English-speaking readers to associate the prediction with the two females. To compensate this culture-specific loss, Hawkes \& Minford explain the homophones in detail as follows: 
The jade belt in the greenwood hangs,

The gold pin is buried beneath the snow (Hawkes, Volume I, 1973, p. 133).

The picture is a simple rebus. Two trees make up the Chinese character for "Lin", whilst "jade belt" is an inversion of "Dai-yu": the "Dai" of Dai-yu's name really means "eye-black", but it sounds the same as the word for "belt", and $y u$ means "jade". The pile of snow is a rebus for Bao-chai's surname Xue, which sounds the same as the chinese word for "snow"... (Hawkes, Volume I, 1973, p. 529).

For this, the Yangs choose zero compensation, omitting the implicative relation between the song and these names. The couple focus on the literal meaning, and don't make any compensation for the loss caused by literal translation. as follow:

\section{Buried in snow the broken golden hairpin}

And hanging in the wood the belt of jade (Yang \& Yang, Volume I, 2012, p. 94).

\subsubsection{Strategies on Compensation for the Lost Pattern of Chinese Character}

What the pattern of Chinese character indicates has done a great favor for Chinese writers' creation. The characters and radicals in names help transmit the information of Chinese family hierarchy. Furthermore, the characters and radicals in names can help develop relationship among characters. The typical illustration is the names of three main characters, “贾宝玉”, “薛宝钗” and “林黛玉”.

As discussed above, the relation一“木石前盟” (oath between wood and stone) and “金玉良缘” (marriage between gold and jade) is hidden in the three names. When Hawkes \& Minfordcame to this song of prediction, he adopted literal translation:

Let others all command the marriage rites of gold and jade; I still recall the bond of old by stone and flower made (Hawkes, Volume I, 1973, p. 140).

By this way, however, it is hard for English-speaking readers to associate this song with the relationship among the three characters. Therefore, Hawkes \& Minford adopt the strategy of off-line compensation, interpreting the relations in appendix, as follow:

The First song the "marriage of rites of gold and jade" refers to the marriage of Bao-chai (gold) and Bao-yu (jade). "Stone" and "flower" are, of course, the avatars of Bao-yu and Dai-yu... (Hawkes, Volume I, 1973, p. 529).

The Yangs translate this song of prediction literally, too. But they do not make any compensation for the prediction hidden in the names of the three characters. In other words, the Yangs resort to the strategy of zero compensation.

Well-matched, all say, the gold and the jade;

I along recall the pledge between plant and stone (Yang \& Yang, Volume I, 2012, p. 101).

In conclusion, when coming to the culture-specific elements expressed by Chinese homophones, near-homophones and radicals, both Hawkes \& Minford and the Yangs take full advantage of the strategies of off-line compensation and zero compensation. As the culture-specific elements of Chinese character carried by names can not be transmitted within text directly, off-line compensation is favorable. The introduction, appendix and the notes are proper choices to accomplish such a strategy. As to the zero compensation, Hawkes \& Minford ignore the original content flatly, whereas the Yangs render the literal meaning in to English, which omits the connotative meaning.

By having an in-depth study on the two unabridged translations, it is found that strategies on compensation are adopted to make up the lost culture-specific elements conveyed by names of characters, mainly including on-line, off-line and zero compensation. To achieve these strategies, Hawkes \& Minford and the Yangs apply various methods. 
Table 5. Strategies of compensation for culture-specific elements in names of characters in two translations

\begin{tabular}{|c|c|c|c|c|c|c|}
\hline & \multicolumn{3}{|c|}{ David Hawkes \& John Minford } & \multicolumn{3}{|c|}{ Yang Xianyi \& Gladys Yang } \\
\hline & $\begin{array}{l}\text { On-line } \\
\text { compensation }\end{array}$ & $\begin{array}{l}\text { Off-line } \\
\text { compensation }\end{array}$ & Zero compensation & $\begin{array}{l}\text { On-line } \\
\text { compensation }\end{array}$ & $\begin{array}{l}\text { Off-line } \\
\text { compensation }\end{array}$ & Zero compensation \\
\hline $\begin{array}{l}\text { Chinese } \\
\text { Naming }\end{array}$ & $\begin{array}{l}\text { Annotation } \\
\text { in text. }\end{array}$ & & $\begin{array}{l}\text { Transliteration; } \\
\text { school name substituting } \\
\text { courtesy name; omission; }\end{array}$ & & $\begin{array}{l}\text { Notes of characters' } \\
\text { names. }\end{array}$ & $\begin{array}{l}\text { Transliteration } \\
\text { school name } \\
\text { substituting courtesy } \\
\text { name }\end{array}$ \\
\hline $\begin{array}{l}\text { Family } \\
\text { Hierarchy }\end{array}$ & $\begin{array}{l}\text { Semantic } \\
\text { translation }+ \\
\text { transliteration }\end{array}$ & $\begin{array}{l}\text { Introduction of } \\
\text { characters; } \\
\text { Dendrogram of the } \\
\text { Jias and Wangs. }\end{array}$ & $\begin{array}{l}\text { Transliteration; transfer; } \\
\text { omission. }\end{array}$ & $\begin{array}{l}\text { Semantic } \\
\text { translation }+ \\
\text { transliteration }\end{array}$ & $\begin{array}{l}\text { Dendrogram of the } \\
\text { Jias; }\end{array}$ & $\begin{array}{l}\text { Transliteration; } \\
\text { transfer }\end{array}$ \\
\hline $\begin{array}{l}\text { Chinese } \\
\text { Character }\end{array}$ & & $\begin{array}{l}\text { Interpretation of } \\
\text { characters' names } \\
\text { in introduction; } \\
\text { annotation of } \\
\text { characters' names } \\
\text { in appendix. }\end{array}$ & Omission. transliteration & & $\begin{array}{l}\text { Notes of characters' } \\
\text { names. }\end{array}$ & $\begin{array}{l}\text { Omission; literal } \\
\text { translation }\end{array}$ \\
\hline
\end{tabular}

Strategy of on-line compensation transmits culture-specific elements timely and intuitively. To be short and succinct to enhance English-speaking readers' interest and ease their memory burden, on-line compensation usually makes partial compensation for the source language culture. In table 6 , it is noticed that translation methods, such as semantic translation and annotation in text, are utilized to realize on-line compensation in two translations.

Besides the strategy of on-line compensation, off-line compensation is also chosen by the translators, which is a significant strategy to compensate the lost culture-specific elements.

Hawkes \& Minford adopt the strategy of off-line compensation, which is realized through the following translation methods: note on spelling, interpretation of names of the characters in introduction and appendix, introduction of characters, and the dendrogram of the Jias and Wangs. (see table 6) The note on spelling explains Chinese Pinyin system and pronunciation in detail to make a compensation for Pinyin. By citing numerous names of characters, Hawkes \& Minford help English-speaking readers to be familiar with Chinese pronunciation. When talking about the intention of the writers of the original novel in introduction, Hawkes \& Minford state the meaning of homophone of the surnames “贾” (Jia) and “甄” (Zhen) and the profound meaning of “贾宝玉” (Jia Baoyu). Additionally, Hawkes \& Minford accounted for names of some characters at length in appendix, especially the names relating to predictions and songs in Chapter 5. At this part, the compensation provide amount of culture-specific elements about the names of some characters to enhance English-speaking readers' understanding about the figures of these characters. In the part, titled "Characters in Volume", Hawkes \& Minford declare the brief background of each character. For English-speaking readers, it is a huge challenge to remember about seven hundreds names and have a clear idea about their roles. So by this way, it is convenient for English-speaking readers to check and understand the information about the characters in the novel. In the dendrogram, Hawkes \& Minford account for the family relationship of main characters in the Jias and Wangs, like the relation between man and wife, between parent and child and among siblings.

The Yangs employ the strategy of off-line compensation, which is realized through the following translation methods: interpretation of the names of the characters in introduction, notes on the names of the characters and dendrogram of the Jias (see table 5). In introduction, the Yangs make great efforts to introduce the brief story and the relationship among main characters. Moreover, in the dendrogram, they state not only the family relationship of main characters in the Jias, such as the relation between man and wife, between parent and child and among siblings and between master and maid. In appendix, they make a explanation on the connotative meaning of the names of some characters, for example, “李纨” ( $\mathrm{Li}$ Wan) who has school name and courtesy name.

The Yangs also adopt zero compensation in their translation, which is realized through the following translation methods: substitution, omission and transfer principally (see table 5). They prefer to replace courtesy names of characters with their school names to a large extent. Additionally, facing with the extensive culture-specific elements contained in the names of characters, The Yangs resort to omission and transfer reluctantly in order to make the characters much easier to be understood. Nevertheless, the original way is crucial to transmit Chinese traditional cultural elements. This strategy is reasonable to some extent. English name structure is transverse, 
like this: "Given name + Middle name + Surname", while ancient Chinese name structure is longitudinal, "Surname + School name" and "Surname + Courtesy name". (Huang, 2001, pp. 60-64; Zhang, 2007, pp. 68-71) Therefore it is hard for English-speaking readers to comprehend such a Chinese naming system, and it is a great burden for their memory. That is why Hawkes \& Minford omits the courtesy names of the characters.

\section{Conclusion}

It is almost impossible to find out the equivalents for the numerous culture-specific elements carried by the names of the characters in Hong Lou Meng in English naming system. To help English-speaking readers have a better understanding of the names of the characters, translators have to make adequate compensation for the lost culture-specific elements in names. In this article, the culture-specific elements in the names of the characters are classified into Chinese naming, Chinese family hierarchy and Chinese character. And the strategies for translating culture-specific elements in names involve on-line compensation, off-line compensation and zero compensation in two unabridged translations. On-line compensation is the major one, which is timely and intuitive, but make partial compensation; off-line compensation is a necessary strategy for English-speaking readers to have a better understanding of the characters and the novel; on account of attracting readers' interests and easing their memory burden, zero compensation is practicable. However, while treating the same culture-specific elements in the names of the characters, different translators may realize the same strategy of compensation by adopting different translation methods as what mentioned above. To realize the strategy of on-line compensation, Hawkes \& Minford adopt two methods, annotation in text and semantic translation plus transliteration, while the Yangs use semantic translation plus transliteration. To achieve the strategy of off-line compensation, the methods, introduction of characters, dendrogram of the Jias and Wangs, interpretation of characters' names in introduction, annotation of characters' names in appendix are utilized by Hawkes \& Minford, and note of the names of characters and dendrogram of the Jias are used. As to the strategy of zero compensation, Hawkes \& Minford adopt transliteration, substitution, omission and transfer. The Yangs take advantage of the methods, transliteration, substitution, omission, transfer and literal translation. In short, when translating the names with abundant culture-specific elements in traditional Chinese novels, it's necessary initially to classify the culture-specific elements into certain types. While choosing the strategies and translation methods on compensation for the lost culture-specific elements in names, it's better to have readability of the translation and easy understanding of the characters in mind.

\section{References}

Cao, X. Q., \& Gao, E. (2008). Hong Lou Meng. Beijing: The People's Literature Publishing House.

Chi, F. (2007). The personal names in Hong LouMeng. Beijing: Xinhua Press.

Editorial department of Commercial Press (Ed.). (2009). Ci Yuan. Beijing: Commercial Press.

Fan, Z. (2010). An applied theory of translation. Beijing: Foreign Language Teaching and Research Press.

Fang, M. Z. (2011). A dictionary of translation studies in China. Shanghai: Shanghai Foreign Language Education Press.

Hawkes, D., \& Minford, J. (1973-1982). The story of the stone (volume I, II, III, V, IV). London: Penguin Group.

Huang, W. H. (2001). English name and culture. Journal of Basic English Education, 1, 60-64. http://dx.doi.org/10.3969/j.issn.1009-2536.2001.01.016

Ince, D. (2007). Oxford dictionary of the internet. Shanghai: Shanghai Foreign Language Press.

Liu, J., \& He, G. (2011). A general introduction to translation. Beijing: ForeignLanguage Teaching and Research Press.

Liu, L. Y. (2010). An analysis on the minor characters' names in Hong Lou Meng's two translations. Journal of Language and Literature Studies, 2, 55-56.

Lv, Q., \& Guan, X. Z. (2011). The translation strategy of personal names in Hong Lou Meng: amanipulation approach. College English, 2, 263-270.

Ma, H. J. (2003). Category and application of translation compensation methods. Foreign Languages and Their Teaching, 10, 37-39.

Publication committee (Ed.). (2007). The New Oxford Dictionary. Shanghai: Shanghai Foreign Language Press.

Qi, H. M. (2007). Language culture hid in personal names' affixes in Hong Lou Meng. The Dream of Red Mansion, 2, 223-238. 
Tan, S. L. (2009). Translation of personal names in Hong Lou Meng—Based on DirkDelabastita's theory of pun translation (Doctoral dissertation, Central South University, China).

Xia, T. D. (2004). The translation strategies of personal names in Hong Lou Meng's two translations. Collected Papers of Hong Lou Meng's Translation Study, 135-154. Tianjin: Nankai University Press.

Yang, X. Y., \& Yang, G. (2012). The dream of red mansion. Beijing: Foreign Language Press.

Zhang, D. E. (2007). Exploration on Chinese names and English names from a cultural aspect. Journal of Beijing Union University, 2, 68-71. http://dx.doi.org/10.3969/j.issn.1672-4917.2007.02.015

Zhang, J. P., \& Cai, Q. (2013). Young maids' names in Hong Lou Meng and their translations. Journal of Jiangxi University of Science and Technology, 6, 107-111.

Zhang, X. X. (2012). A contrastive study of name translation in two unabridged version in Hong Lou Meng (Doctoral dissertation, Ocean University of China, China).

\section{Copyrights}

Copyright for this article is retained by the author(s), with first publication rights granted to the journal.

This is an open-access article distributed under the terms and conditions of the Creative Commons Attribution license (http://creativecommons.org/licenses/by/4.0/). 